\title{
Investigating Factors Affecting Knowledge Sharing Intentions among Islamic Banking Employees: A TRA Perspective
}

\author{
Muhammad Waqar ${ }^{1}$, Muhammad Anwar ul Haq ${ }^{2 *}$, Muhammad Usman ${ }^{3}$ \\ ${ }^{1}$ Lecturer, Department of Management Sciences, University of Management and Technology, \\ Sialkot, Pakistan \\ ${ }^{2}$ Assistant Professor, Department of Management Sciences, University of Gujrat, Gujrat, Pakistan \\ ${ }^{3}$ Assistant Professor, Department of Management Sciences, University of Gujrat, Gujrat, Pakistan
}

\section{Keywords}

Knowledge Sharing (KS)

Attitude Towards

Knowledge Sharing

Intention to Knowledge Share

Islamic Banking

Received: 04 June 2018

Accepted: 22 June 2018

\begin{abstract}
This study investigates Knowledge Sharing (KS) in Islamic banks. Fishbein's Theory of Reasoned Action (TRA) has been used as a theoretical framework. Close ended questionnaire was used to gather data from employees of Islamic banks. This study examined the effect of independent variables i.e., Anticipated Extrinsic Rewards (AER), Sense of Self-Worth (SSW), and Organization-Based Self-Esteem (OBSE) and Anticipated Reciprocal Relationship (ARR) on variables i.e., Intentions towards Knowlede Sharing (IKS), Attitude to Knowledge Sharing (ATKS). The objective was to find out the strongest predictor. Structural Equations Modeling (SEM) has been applied to examine the hypothesized relations. Analysis shows strong association between IKS and ATKS. Hypotheses relating SSW and OBSE were endorsed. While ARR and AER did not influence KS attitude, yet the OBSE was found to have strongest impact on KS attitude. In the light of results, it is suggested that Islamic banks should focus on other ways to encourage KS rather than investing in reward systems. They should also focus on relationship improvement and also ensure support to employees by means of carrier planning and job security.
\end{abstract}

KAUJIE Classification: J32, V12, W

JEL Classification: C5

(C) 2018 JIBM. All rights reserved.

\section{INTRODUCTION}

The significance of KS has been widely recognized by several researchers (e.g., Alavi \& Leidner, 2001; Berman, Down, \& Hill, 2002; Bock, Zmud, Kim, \& Lee, 2005; and Irma, 2001). It has been recognized as a most critical element of knowledge management (Casimir, Lee, \& Loon, 2012; Huang \& Huang, 2012; Javernick-Will, 2011). Many organizations are focusing on knowledge management and apprehending its importance for competitive advantage (Wang, Sharma, \& Cao, 2016). According to Wu, Yeh, and Hung (2012), KS comprises

\footnotetext{
*Corresponding author: Muhammad Anwar ul Haq

${ }^{\dagger}$ Email: anwar.haq@uog.edu.pk
} 
generating new ideas, transfer of ideas, sharing of information, articulating experiences, and developing best practices amongst employees. Individuals are sole owners of the knowledge (Nonaka \& Konno, 1998), and sharing of knowledge depends on their intentions. Ethically, Organizations cannot force employees to share their knowledge and there is no consensus on factors that encourage employees to share their knowledge. It is hence, utmost essential to know that what motivates employees to share knowledge (Ozlati, 2012).

Some researcher found that individuals exchange their knowledge for personal benefits (Hsu, Ju, Yen, \& Chang, 2007) whereas, Chiu, Hsu, and Wang (2006) found contrary results. Some studies found that people share knowledge with the expectation to receive respect, being viewed as skilled, knowledgeable, and for improving self-worth and self-esteem (Butler, Sproull, Kiesler, \& Kraut, 2002; Chiu et al., 2006; Zhang \& Hiltz, 2003). Zhang, Chen, Vogel, and Guo (2009) found, on the other hand, that individuals do not exchange knowledge due to reputation. Therefore, more exploration is required to explore key motivational factors behind KS (Sharma \& Singh, 2012). Specifically, researchers may examine the impact of factors on different sectors and industries (Seba, Rowley, \& Lambert, 2012).

Knowledge sharing attitude and intention have been studied extensively in developed countries that have strong infrastructure with transparent organization system whereas limited researches have been conducted in developing countries, specifically in Islamic banking sector. This research study's target population is from Islamic banks. Islamic banks have gained enormous popularity in both Muslim and Non-Muslim world. The total assets of all Islamic banks across the world were about US\$ 2 trillion in 2017, and so far 755 Islamic banks registered across the world (Edbiz, 2015). In Pakistan as well, Islamic banks are flourishing at significant rate, Total Islamic bank branches till end of March 2018 were 2589 in Pakistan (State Bank of Pakistan, 2018).

The increase in awareness of Islamic values has resultantly increased the demand for Islamic banks' interest free products (Khir, Gupta, \& Shanmugam, 2007). The demand of Islamic banks' interest free products is also increasing in Pakistan. This requires improvement in the products as well as awareness about Sharī'ah-compliant products. These days, clients are well educated and are highly informative about banking services and products; therefore, demand advanced and customized products and services (Arshad, Aslam, Razi, \& Ali, 2011). In adapting to bank customers' requirements, it is crucial whether the employees of Islamic banks have sufficient knowledge of Islamic banking products. Zainol, Shaari, and Ali (2009) found that the Islamic bank staff had limited knowledge of Islamic banking products, they did not exactly comprehend the distinction amongst Islamic and conventional banking systems (Harun, Rashid, \& Hamed, 2015). One of the reasons behind this is that most of the Islamic banks' personnel are recruited in the conventional banks, and they have shifted to Islamic Bank for better opportunities without having orientation and sufficient knowledge about Islamic banking. It is essential, however, that the Islamic banks' employees might have a broader understanding of Islamic banking products so that the emerging system could have a competitive advantage among banking industry. This understanding could be achieved by sharing knowledge. It is only possible if employees are encouraged to share knowledge and experiences. Hence, there is need to investigate what motivates 
Islamic bank employees to share knowledge. In this perspective, present study is the need of the time.

Several factors regarding KS behavior have been studied by different authors among different sectors. Bock and Kim (2001) examined the factors like expected rewards, expected contribution and expected association among public sector employees. Kwok and Gao (2005) studied extrinsic motivation, channel richness and absorptive capacity among university students. Bock et al. (2005) studied AER, reciprocal relationship and SSW among Korean private sector employees. Likewise Lin (2007) selected a sample from Taiwanese private companies and studied perceived organizational rewards, reciprocal relationship, enjoyment in helping others and knowledge self-efficacy. Palo and Charles (2015) studied expected organizational benefits, reputational enhancement, loss of knowledge power and organizational commitment among sales persons. Recently, Fullwood and Rowley (2017) investigated several beliefs and organizational culture among UK academics. It implies that different factors show significant association with KS in different sectors. However, the question here is that whether and to what extent these factors will influence KS among Islamic banks employees. In answering the above question, this study is to develop a model appropriate in the context of Islamic banks to investigate the motivational factors that significantly influence Islamic bank employees.

\section{REVIEW OF LITERATURE AND HYPOTHESES}

\section{KS and Motivational Factors}

Different researchers and authors have defined KS differently (Scott, 1999). Ling, Sandhu, and Jain (2009), have explained KS as the distribution of knowledge. Dyer and Nobeoka (2000) are of the view that KS is the combination of activities that include knowledge exchange and helping others by improving their learning capacity. Whilst, Wang and Noe (2010) define KS as generating new ideas, solving problems together and employing policies and procedures.

Davenport and Prusak (1998) argued that sharing of knowledge solely depends on the owner of the knowledge, and sharing of it is habitually unnatural (Davenport, 1996). Sharing of knowledge can't be forced by organization, it is a personal choice of the employees. Naturally, people are hesitant to share knowledge and they can't be easily motivated to share (Staples \& Webster, 2008). In accordance with TRA, human's attitude and intention can be influenced by several factors, and it can be opted to explain human behaviors (Fishbein \& Ajzen 1977).

Several models have been proposed that opted TRA to understand factors influencing KS, employees attitude and intentions (Bock et al., 2005; Lin \& Huang, 2013). These models were different from each other in respect of dependent and independent variables. Like, Bock et al. (2005) studied influencing factors like AER, reciprocal relationship, and selfworth with knowledge sharing attitude and intentions. Similarly, Lin and Huang (2013) studied knowledge sharing intention and attitude with self-efficacy and satisfaction in helping other employees. Whilst Seba et al. (2012) explored effect of leadership, trust, or- 
ganizational structure, rewards, time and IT on knowledge sharing attitude and intentions. Palo and Charles (2015) studied influencing factors including perceived organizational incentives, reciprocal benefits, reputation enhancement, loss of knowledge power (superiority which one feels based on his/her knowledge), and organizational commitment with attitude and intentions. Similarly recently Fullwood and Rowley (2017) examined factors affecting KS among UK academics. Despite several studies, there is lack of assent on the key influencing factors of KS.

In current study, TRA is opted to understand effects of motivational factors on attitude and intentions of Islamic banks' employees. The influence of four factors has been explored in the current study namely AER, ARR, SSW and OBSE; each factor has its own characteristics and is supposed to affect knowledge sharing attitude and intention.

\section{ATKS and IKS}

IKS is a person's beliefs that he would actually share knowledge or not (Bock et al., 2005). In accordance with TRA, employee's intention is determined by their attitude. Several studies used both KS attitude and intention as dependent variables. The relationship between attitude and intention has been investigated by several researchers who found strong positive relationship between the both. For example, Lin (2007) studied attitude and intention of employees of a Taiwanese's company and found positive strong relationship between both. Likewise Bock et al. (2005) studied KS among employees of 27 Korean organizations and found positive relation between attitude and intention of KS. Palo and Charles (2015) studied KS among salespersons and found positive relationship between both attitude and intention. Several other researchers also found strong positive influence of attitude on intention (Chennamaneni, Teng, \& Raja, 2012; Jeon, Kim, \& Koh, 2011). In accordance with Islamic perspective it was argued that religion influences attitude, intention, behavior and plays a key role in modeling man's daily conducts (Alam, Janor, Zanariah, \& Ahsan, 2012). The Islamic teachings provide that there is a strong relationship between individuals' faith and conduct. Thus, we propose that attitude towards KS influences bank employees' IKS. In the light of above assertion, it is hypothesized that:

H1: ATKS positively affects IKS among employees of Islamic banks.

\section{AER and ATKS}

AER refers to the reward that one expects for sharing knowledge (Bock et al., 2005). Individuals expect to get extrinsic rewards for sharing tacit/explicit knowledge with others. Lamb (2001) and Liu (2008) have suggested that organizations should adopt reward system for KS. Similarly, Ford and Staples (2010), argued that rewards and incentives play crucial role to highlight significance of KS activities of the employees. For Vajjhala (2013), AER are positive for motivating employees to perform preferred behaviors.

Seba et al. (2012) maintained that the effect of rewards on sharing knowledge may vary with the kind of rewards given to employees. Søndergaard, Kerr, and Clegg (2007) found that organizational rewards like bonuses, better job assignment, job promotions, were crucial for motivating employees to add knowledge to repositories. Similarly, Bock and Kim 
(2001) studied that employees who believe that they will get high incentives by sharing and using knowledge are more expected to support knowledge management system. Researchers explain that insufficient rewards might decrease KS (Chen \& Hung, 2010; Osterloh \& Frey, 2000). Likewise, absence of incentives may cause individual's motivation level to diminish, or feel punished, which ultimately influences KS attitudes negatively (Vuori \& Okkonen, 2012; Zhang \& Fai-Ng, 2012). Giving rewards and acknowledging shared knowledge not only improves the KS level of the employees, but also decreases the probability for knowledge to be lost (Gupta, Joshi, \& Agarwal, 2012; Vajjhala, 2013; Zhang \& Fai-Ng, 2012).

Alam et al. (2012) argued that Islamic banks employees have limited knowledge of Islamic banking. Baba and Amin (2009) found that some of the Islamic banks employees were unable to distinguish between Islamic banking system and conventional banking system, which may also increase confusion among customers. The limited knowledge is due to lack of KS among Islamic banking employees and thus it is believed that by motivating employees though extrinsic rewards their ATKS can be changed.

In accordance with the TRA, employees' attitude is the result of beliefs and expectations. It is supposed that Islamic banks employees who believe to receive extrinsic rewards by sharing knowledge, will develop positive ATKS. So, it is hypothesized that:

H2: AER will positively affect ATKS among employees of Islamic banks.

\section{ARR and ATKS}

ARR is explained as the extent to which employees believe that they can develop better reciprocal relationships with other employees through KS (Bock et al., 2005). Researchers have found that reciprocal advantages can give compelling inspiration to encourage KS, and ultimately support to achieve long-term common goals (Bock et al., 2005; Søndergaard et al., 2007). Huang, Davison, and Gu (2008) found that employees who wish to create good relationship with other employees or assume to get knowledge from different employees in the future, they usually share more knowledge with others. In a team context, ARR increases team spirit, which directly influences and raises the intrinsic motivation to cooperate and to share knowledge (Osterloh \& Frey, 2000).

ARR has been studied in different settings of different countries. For example, Bock et al. (2005) examined ARR at managerial level in Korean organizations. They found that ARR have significant positive effect on KS attitudes. Pai (2006) studied KS in online communities and found that KS is supported by a strong sense of reciprocity. Tohidinia and Mosakhani (2010) studied KS behavior among employees of Iranian oil industry and found that ARR positively affects knowledge sharing attitudes. Palo and Charles (2015) studied KS among salespersons working in different sectors like insurance, banking, manufacturing, and pharmaceutical; they found significant positive influence of ARR on KS.

Harun et al., (2015) have indicated that today's banking is not only to sell products and services, but also to provide knowledge to customers. Like other organizations, Islamic banks should also focus on KS. In this regards, the most common methods used by banks include team-oriented brainstorming (Shih, Chang, \& Lin, 2010), and forming communities of practitioners. Both methods could be beneficial for Islamic banks if their employees 
believe that they should develop better relationship by sharing knowledge. As argued in TRA, beliefs make attitude, so those Islamic bank employees who believe that KS could be beneficial in the future for making better relationships are likely to share knowledge and thus have positive attitude towards sharing. So, it is hypothesized that:

H3: ARR will have positive effect on ATKS among employees of Islamic banks.

\section{SSW and ATKS}

Employee's belief that he will support his organization by KS behavior is known as "SSW" (Phan, 2013). For Bandura (1994), it is person's belief regarding his competence to produce desired results. Positive feedback is very vital in KS environment and is important facilitator. Positive feedback ensures that employee's behavior is acceptable, and it encourages employee to continue KS (Kinch, 1973). Appreciation and effectiveness of the knowledge shared improves employees' SSW. Individuals will likewise be additionally eager to contribute via KS while they find that their shared knowledge is significant and practically helpful to employees working with them (Cabrera \& Cabrera, 2002). Huber (2001) found that, the SSW impacts employees' behavior in the favor of organizational norms and prevailing employees. Those employees who get continuous feedback and also get understanding as to how their shared knowledge supported individuals to share more knowledge than others, and ultimately motivated employees to develop positive knowledge sharing attitude (Phan, 2013).

Bock et al. (2005) found that SSW not only helps in self-evaluations of employee's knowledge through KS activity, but also influences employees' ATKS. Phan (2013) studied employees of Vietnam and supported that SSW has positive impact on knowledge sharing attitude. Similarly Tohidinia and Mosakhani (2010) confirmed that higher the SSW results in higher knowledge sharing attitude. Ye, Chen, and Jin (2006) argued that self-worth was among key antecedent of ATKS. Likewise, managers' positive feedback about employees knowledge contribution and achievements may enhance Islamic banking employees' SSW which ultimately enriches KS behavior (Shih et al., 2010). TRA and above discussion conclude that beliefs are key factors for developing attitude and Islamic banking employees who are of the belief that they can contribute in organizational growth by sharing knowledge when they have positive ATKS. Thus, it is hypothesize that:

H4: SSW positively affects employees' ATKS among employees of Islamic banks.

\section{OBSE and ATKS}

The OBSE concept was first coined by Pierce, Gardner, Cummings, and Dunham (1989). This concept has captured extensive attention ever since. OBSE is "the degree to which organizational members believe that they can satisfy their needs by participation in roles within the context of an organization" (Pierce \& Gardner, 2004, p. 265). It also expresses "an employee's evaluation of his or her personal adequacy and worthiness as an organizational member" (Pierce \& Gardner, 2004, p. 308). OBSE is conceptually different from self-esteem. It could be defined as one's belief about self-worth as an organizational mem- 
ber.

Several researchers have studied relationship between self-esteem and attitude and also between OBSE and employee attitudes (e.g., Brockner, 1988; Korman, 1970; Yang, 2007). It was found that self-esteem predicts employee's attitude and behavior (Brockner, 1988; Judge \& Bono, 2001; Korman, 1970; Pierce \& Gardner, 2004). They also found that employees who have high level of OBSE might probably share knowledge with other employees because they are of believe that they support their organization through KS. Phan (2013) studied OBSE as an antecedent of knowledge sharing attitude among employees of Taiwanese company, whereas, he found no positive relationship between OBSE and ATKS. Banker's self-esteem is their perceived evaluation about themselves. Brown and Marshall (2006) found banker's self-esteem to be a key component to recognize banker's successful development, and positive feelings about themselves. Self-esteem is the combination of self-confidence and self-respect which could be achieved if employees are fully equipped with knowledge. Thus, it is hypothesized that:

H5: OBSE positively affects ATKS among employees of Islamic banks.

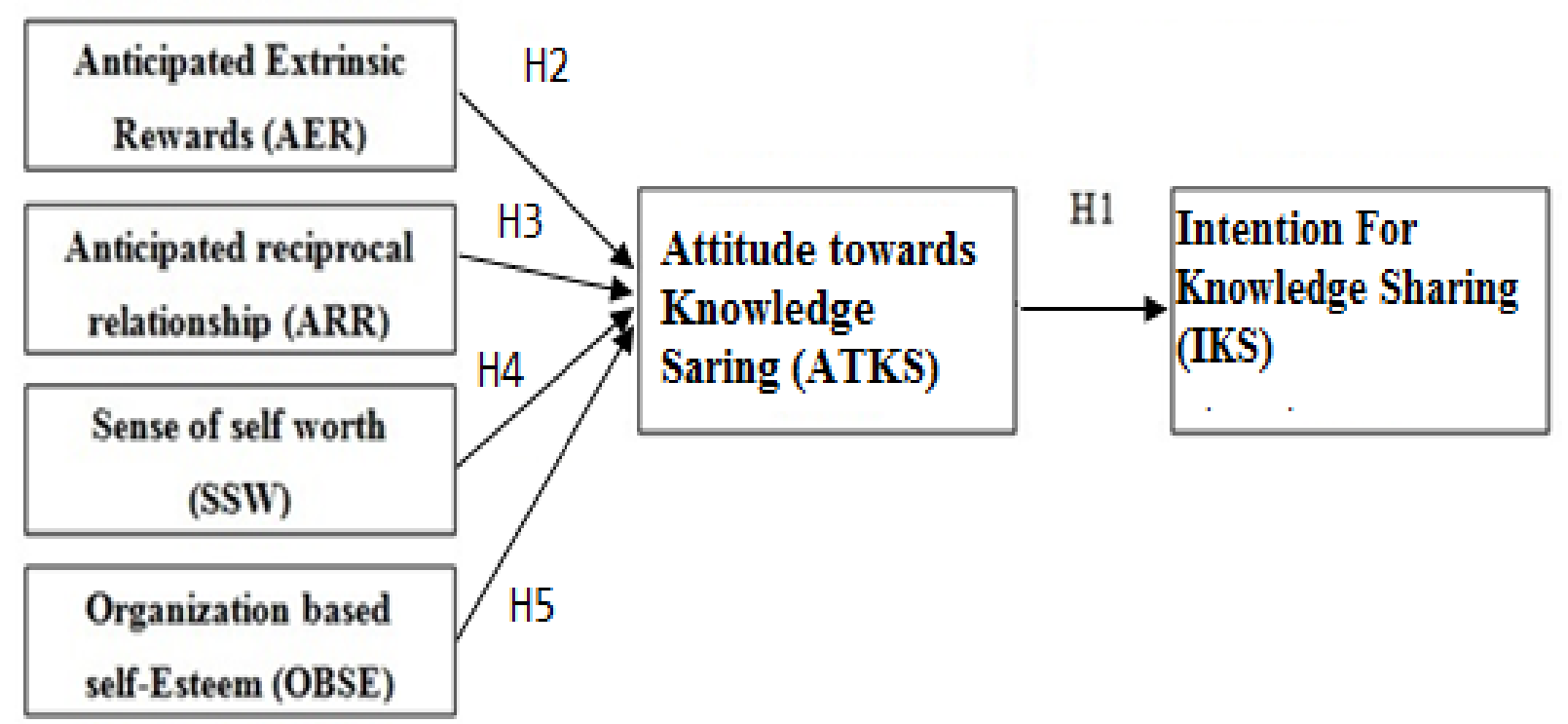

FIGURE 1. Conceptual Framework

\section{METHODOLOGY}

\section{Population and Sampling}

The population for current study are the employees working in Islamic banks operating in Pakistan. Total 500 questionnaires were distributed among employees, while 390 filled questionnaires were received back. After preliminary scrutiny, questionnaires having more than 10\% missing values were discarded; remaining 313 questionnaires were selected in which 22 questionnaires were found having missing values. For imputation of missing values mean imputation method is adopted. The overall questionnaire response rate was $78 \%$, and the usable questionnaire response rate was $62.60 \%$. 


\section{Measures}

The current study used questionnaire consisting of 29 total questions measuring 6 constructs. Each construct had multiple items, scales were adopted from previous studies that were prevalidated measures in literature. Table 1 shows scales along with their respective author's reliabilities. Items were measured by 5 -point Likert Scale where $1=$ "Strongly disagree" and 5 = "Strongly agree". Questionnaire also included categorical questions such as age, gender, educational level, designation, experience with current organization and total professional expereience.

AER measures: The AER was measured by using three (3) items scale develop by Bock and Kim (2001), In his study Cronbach's $\alpha$ for AER was 0.83. Example item: "I expect to receive monetary rewards in return for my KS".

ARR measures: The study measures ARR by using five (5) items scale develop by Bock et al. (2005). In their study, Cronbach's Alpha for ARR was $\alpha=0.71$. Example item: "My KS would strengthen the ties between existing members in the organization and myself".

OBSE measures: Scale having six (6) items developed by Pierce et al. (1989) was used to measure an employee's OBSE. In their study Cronbach's Alpha for OBSE was $\alpha=0.91$. Example item: "If I share the knowledge, I will feel that I count around here".

SSW measures: SSW was measured by using 5-items of scale developed by Bock et al. (2005). In their study, Cronbach's Alpha for SSW relationship was $\alpha=0.95$. Example item: "My KS would help other members in the organization to solve their problems".

Employees' ATKS measures: Employees' knowledge sharing attitude was measured by five 5-items scale adopted from Bock et al. (2005). In their study Cronbach's Alpha for ARR was $\alpha=0.92$. Example item: "My KS with other organizational members is good".

Employees' IKS measure: Employees IKS was measured by five 5-items scale, adopted from the study of Bock et al. (2005). In their study Cronbach's Alpha for ARR was $\alpha=$ 0.93. Example item: "I will share my work reports and official documents with members of my organization more frequently in the future". 
TABLE 1

Sources of Measurement Constructs

\begin{tabular}{llll}
\hline \hline Variables & Items & Measures adapted from & Cronbach alpha $(\alpha)$ \\
\hline AER & 3 & (Bock \& Kim, 2001) & 0.83 \\
ARR & 5 & (Bock et al., 2005) & 0.71 \\
OBSE & 6 & (Pierce et al., 1989) & 0.91 \\
SSW & 5 & (Bock et al., 2005) & 0.95 \\
ATKS & 5 & (Bock et al., 2005) & 0.92 \\
IKS & 5 & (Bock et al., 2005) & 0.93 \\
\hline \hline
\end{tabular}

\section{Sample Profile}

Demographic summary of sample is shown in Table 2 below. According to Table 2, majority of the respondents were male 245 (78.3\%), while in terms of age, the respondents were dominated by young age group i.e., 21-30 years. In respect of education, it was found that minimum education of respondents was bachelor's degree while $202(64.5 \%)$ respondents held master's degree. For recording of experience level, three categories were made for uniformity of the responses; results shows that most of the respondents were of officer level - 123 (39.3\%). Further, in respect of experience, on average, respondents' experience with their current banks is 5.9 years $(\min =1, \max =23)$ and total professional experience is on average 7.5 years $(\min =1, \max =24)$.

TABLE 2

Participant Demographics $(n=313)$

\begin{tabular}{lll}
\hline \hline Statement & Frequency & Percentage (\%) \\
\hline Gender & & \\
Male & 245 & $78.3 \%$ \\
Female & 68 & $21.7 \%$ \\
Ages (Years) & & \\
$21-30$ & 166 & $53.0 \%$ \\
$31-40$ & 127 & $40.6 \%$ \\
$41-50$ & 15 & $4.8 \%$ \\
51-Above & 5 & $1.6 \%$ \\
Education (Numbers) & & \\
Bachelor's degree & 106 & $33.9 \%$ \\
Master's degree & 202 & $64.5 \%$ \\
MS/M.Phil degree & 5 & $1.6 \%$ \\
Experience Level (Numbers) & & \\
Junior Officer & 96 & $30.7 \%$ \\
Officer & 123 & $39.3 \%$ \\
Manager & 94 & $30.0 \%$ \\
\hline \hline
\end{tabular}


Table 2 Continue...

\begin{tabular}{lll}
\hline \hline Statement & Frequency & Percentage (\%) \\
\hline Experience with this Organization & & \\
$0-3$ & 132 & $42.2 \%$ \\
$4-7$ & 104 & $33.2 \%$ \\
$8-11$ & 40 & $12.8 \%$ \\
$12-15$ & 19 & $6.1 \%$ \\
16 Above & 18 & $5.8 \%$ \\
Experience with this Organization & & \\
$0-3$ & 79 & $25.2 \%$ \\
$4-7$ & 112 & $35.8 \%$ \\
$8-11$ & 63 & $20.1 \%$ \\
$12-15$ & 32 & $10.2 \%$ \\
16 Above & 27 & $8.6 \%$ \\
\hline \hline
\end{tabular}

\section{Factor Analysis}

Exploratory Factor Analysis was performed through SPSS 21. Results show that all items have higher loading than recommended value. Therefore, no item is excluded. It shows that AER have 3 factors, ARR is defined by 5 factors, SSW by 5 factors, OBSE by 6 factors, ATKS by 5 factors, and IKS by 5 Factors.

TABLE 3

Factor Loading

\begin{tabular}{lllllll}
\hline \hline & 1 & 2 & 3 & 4 & 5 & 6 \\
\hline AER1 & .874 & & & & & \\
AER2 & .896 & & & & & \\
AER3 & .766 & & & & & \\
ARR1 & & .623 & & & & \\
ARR2 & & .698 & & & & \\
ARR3 & & .597 & & & & \\
ARR4 & & .597 & & & & \\
ARR5 & & .400 & & & & \\
SSW1 & & & .528 & & & \\
SSW2 & & & .781 & & & \\
SSW3 & & & .710 & & & \\
SSW4 & & & .551 & & & \\
SSW5 & & & .663 & & & \\
OBSE1 & & & & .601 & & \\
OBSE2 & & & .779 & & \\
OBSE3 & & & & .767 & \\
\hline \hline
\end{tabular}


Table 3 Continue...

\begin{tabular}{lllllll}
\hline \hline & 1 & 2 & 3 & 4 & 5 & 6 \\
\hline OBSE4 & & & .596 & & \\
OBSE5 & & & .792 & & \\
OBSE6 & & & .705 & & \\
ATKS1 & & & & .567 & \\
ATKS2 & & & & & .509 & \\
ATKS3 & & & & & .651 & \\
ATKS4 & & & & & .632 & \\
ATKS5 & & & & & .755 & \\
IKS1 & & & & & & .674 \\
IKS2 & & & & & .629 \\
IKS3 & & & & & & .837 \\
IKS4 & & & & & & .889 \\
IKS5 & & & & & & \\
\hline \hline
\end{tabular}

\section{Descriptive Measures}

Table 4 gives understanding into the relationship of the factors for this study. This Table displays items number of each construct, Composite reliabilities, Cronbach's alpha, Average Variance Extracted (AVE), means, standard deviations, and correlations between all variables used in this study.

There are no convergent and discriminant validity issues. Reliability is measured by Cronbach's alpha and all values are found above the recommended threshold, i.e., 0.60 (Gliem \& Gliem, 2003; Hair, Black, Babin, Anderson, \& Tatham, 1998; Kline, 2011). Reliability is also measured by Composite Reliability (CR); all values have been found above the recommended value of 0.70. AVE is above 0.4, but it is acceptable as Fornell and Larcker argued that if AVE is below 0.5, while CR is higher than 0.6, the construct is yet considered to have established convergent validity (Fornell \& Larcker, 1981).

TABLE 4

Descriptive Statistics

\begin{tabular}{llllllllllll}
\hline \hline Variables & Items & CR & $\begin{array}{l}\text { Cronbach's } \\
\text { alpha }(\alpha)\end{array}$ & AVE & Mean & $\begin{array}{l}\text { Std. } \\
\text { Deviation }\end{array}$ & AER & ARR & SSW & OBSE & ATKS \\
\hline AER & 3 & 0.732 & 0.847 & 0.414 & 2.91 & 1.09 & - & & & & \\
ARR & 4 & 0.858 & 0.712 & 0.670 & 4.03 & 0.591 & $.325^{* *}$ & - & & & \\
SSW & 5 & 0.819 & 0.898 & 0.405 & 3.52 & 0.836 & $.346^{* *}$ & $.529^{* *}$ & - & & \\
OBSE & 6 & 0.728 & 0.820 & 0.477 & 3.62 & 0.808 & $.328^{* *}$ & $.579^{* *}$ & $.655^{* *}$ & - & \\
ATKS & 4 & 0.904 & 0.717 & 0.612 & 3.83 & 0.591 & -.001 & $.336^{* *}$ & $.269^{* *}$ & $.376^{* *}$ & - \\
IKS & 5 & 0.856 & 0.866 & 0.547 & 3.53 & 0.873 & $.242^{* *}$ & $.345^{* *}$ & $.344^{* *}$ & $.375^{* *}$ & $.165^{* * *}$ \\
\hline \hline
\end{tabular}

\section{RESULTS}

The research model was analyzed by SEM using AMOS version 21. For validity and reliability of model, Confirmatory Factor Analysis (CFA) has been performed, whereas structural 
model has been used to access the direction and strength of the proposed relationship.

\section{Measurement Model Evaluation}

For measurement model assessment, CFA has been used. Measurement model analysis confirms the reliability and validity of the adopted scales in new setting. Segars and Grover (1998) recommend that initial model must be modified to get best fit model. After initial testing, 2 items ARR5 and ATKS2 were removed having standardized regression value lower than recommended 0.5 (Kline, 2011). The proposed model was also improved by adding covariance between error terms using Modification Indices (MI), as recommended by Hair, Anderson, Babin, and Black (2010).

TABLE 5

Summary of Goodness of Fit Model

\begin{tabular}{llllll}
\hline \hline Fit Index & $\begin{array}{l}\text { Initial Model } \\
\text { Results }\end{array}$ & $\begin{array}{l}\text { Single Factor } \\
\text { Model }\end{array}$ & $\begin{array}{l}\text { Final Model } \\
\text { Results }\end{array}$ & $\begin{array}{l}\text { Recommended } \\
\text { Criteria }\end{array}$ & $\begin{array}{l}\text { Suggested by } \\
\text { Authors }\end{array}$ \\
\hline x2 & 1133.59 & 1647.86 & 755.26 & - & - \\
Df & 362 & 310 & 295 & - & - \\
x2/df & 3.13 & 5.3 & 2.56 & $<3$ & Bentler and Bonett (1980) \\
GFI & 0.78 & 0.72 & 0.85 & $>0.8$ & Scott (1999), Seyal, Rehman, and Rahim (2002) \\
TLI & 0.80 & 0.65 & 0.87 & $>0.9$ & Hu and Bentler (1999) \\
CFI & 0.83 & 0.69 & 0.90 & $>0.9$ & Bentler and Bonett (1980) \\
RMSEA & 0.083 & 0.118 & 0.071 & $<0.08$ & Hair et al. (1998) \\
AGFI & 0.73 & 0.65 & 0.80 & $>0.8$ & Scott (1999) \\
NFI & 0.77 & 0.65 & 0.84 & $>0.9$ & Bentler and Bonett (1980) \\
\hline \hline
\end{tabular}

Goodness of Fit (GFI) is evaluated by using GFI index, TLI TuckerLewis Index (TLI), CFI (an incremental fit index of improved NFI), Root-Mean-Square Error of Approximation (RMSEA), Adjusted Goodness-of-Fit Index (AGFI), (the ratio between 2 and the degree of freedom $=$ x2/d.f.), and Normalised Fit Index (NFI). Table 4 shows the results of fitness measurement, it implies that initial model and single factor model show poor fit, whereas after recommended modification modified model, results fell into threshold range. Hence, confirming that proposed model had proper fit.

\section{Common Method Bias}

Following strategies were adopted to evaluate the common biased variance: Harman's onefactor method; one-factor CFA and common latent factors. Harman's one factor method was performed using SPSS version 21 . The results show only a $29.22 \%$ variance. The results of principal component analysis on all variables formed six dissimilar factors; only $14.43 \%$ of total variance is represented by first factor, while $68.94 \%$ is represented by all factors together. Single Factor CFA was performed using AMOS version 21 (See Table 4). Similarly, Common latent factor was also performed using AMOS version 21 by taking difference between standardized regression weight with latent factor, and without latent factor for each item shown in Table 6. Result for all three methods show that there was no variance in data. 
TABLE 6

Common Latent Factors

\begin{tabular}{|c|c|c|c|}
\hline & $\begin{array}{l}\text { Estimate } \\
\text { With CLF (A) }\end{array}$ & $\begin{array}{l}\text { Estimate } \\
\text { Without CLF (B) }\end{array}$ & $\begin{array}{l}\text { Difference } \\
\text { (A-B) }\end{array}$ \\
\hline AER1 <- AER_MAIN & 0.799 & 0.759 & 0.04 \\
\hline AER $2<-$ AER_MAIN & 0.826 & 0.934 & -0.108 \\
\hline AER3 $<-$ AER_MAIN & 0.575 & 0.75 & -0.175 \\
\hline ARR1 <- ARR_MAIN & 0.544 & 0.544 & 0 \\
\hline ARR2 $<-$ ARR_MAIN & 0.618 & 0.65 & -0.032 \\
\hline ARR3 $<-$ ARR_MAIN & 0.601 & 0.58 & 0.021 \\
\hline ARR4 <- ARR_MAIN & 0.604 & 0.752 & -0.148 \\
\hline SSW1 $<$-SSW_MAIN & 0.562 & 0.611 & -0.049 \\
\hline SSW2 <-SSW_MAIN & 0.577 & 0.722 & -0.145 \\
\hline SSW3 $<-$ SSW_MAIN & 0.691 & 0.779 & -0.088 \\
\hline SSW4 <-SSW_MAIN & 0.279 & 0.656 & -0.377 \\
\hline SSW5 $<-$ SSW_MAIN & 0.663 & 0.675 & -0.012 \\
\hline OBSE $1<-$ OBSE_MAIN & 0.574 & 0.687 & -0.113 \\
\hline OBSE2 <- OBSE_MAIN & 0.686 & 0.847 & -0.161 \\
\hline OBSE3 $<-$ OBSE_MAIN & 0.721 & 0.837 & -0.116 \\
\hline OBSE4 <- OBSE_MAIN & 0.804 & 0.708 & 0.096 \\
\hline OBSE5 $<-$ OBSE_MAIN & 0.589 & 0.782 & -0.193 \\
\hline OBSE6 $<-$ OBSE_MAIN & 0.798 & 0.817 & -0.019 \\
\hline ATKS $1<-$ IKS_MAIN & 0.619 & 0.56 & 0.059 \\
\hline ATKS3 $<$ - IKS_MAIN & 0.621 & 0.629 & -0.008 \\
\hline IKS $1<$ - IKS_MAIN & 0.617 & 0.641 & -0.024 \\
\hline IKS $2<$ - IKS_MAIN & 0.566 & 0.624 & -0.058 \\
\hline IKS3 <- IKS_MAIN & 0.853 & 0.83 & 0.023 \\
\hline IKS4 <- IKS_MAIN & 0.81 & 0.819 & -0.009 \\
\hline IKS5 $<$ 一 IKS_MAIN & 0.742 & 0.758 & -0.016 \\
\hline ATKS4 <- IKS_MAIN & 0.766 & 0.83 & -0.064 \\
\hline ATKS5 $<$ 一 IKS_MAIN & 0.585 & 0.509 & 0.076 \\
\hline
\end{tabular}

\section{Hypotheses Testing}

Hypotheses between variables were tested using Structural Equation Model (SEM) (see Figure 2). The results show that employees' ATKS has significant effect on employees IKS $(\beta=0.41, p<0.03)$, whereas AER $(\beta=-0.05, p<0.083)$ and ARR $(\beta=0.04, p<0.526)$, have no significant effect on ATKS. SSW ( $\beta=0.14, p<0.007)$, OBSE $(\beta=0.41, p<$ 0.001 ) had significant effect on employees' knowledge sharing attitude. 
TABLE 7

Results of Hypothesis Testing

\begin{tabular}{lll}
\hline \hline Hypothesis & Research Proposed Paths & Coefficient \\
\hline H1 & ATKS $\rightarrow$ IKS & $\left(0.41^{* * *}\right)$ \\
H2 & AER $\rightarrow$ ATKS & $(-0.05)$ \\
H3 & ARR $\rightarrow$ ATKS & $(0.04)$ \\
H4 & SSW $\rightarrow$ ATKS & $(0.14 * *)$ \\
H5 & OBSE $\rightarrow$ ATKS & $\left(0.41^{* * *}\right)$ \\
\hline * $* * p<0.001, * * p<0.05$
\end{tabular}

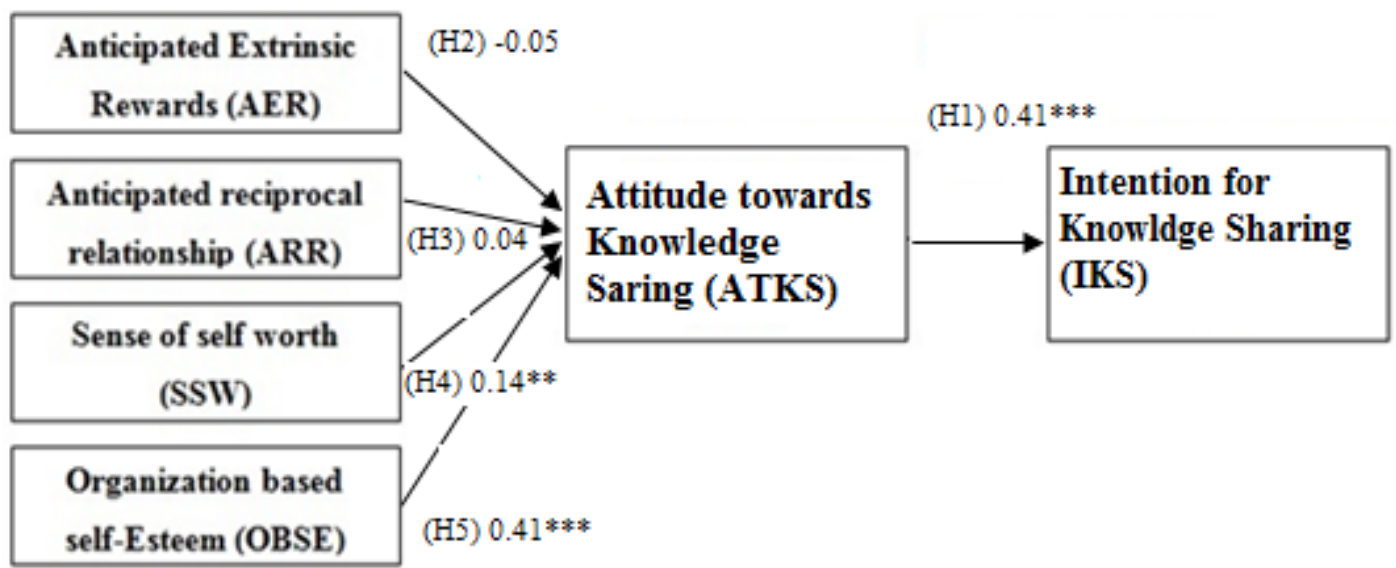

FIGURE 2. Results of SEM

\section{DISCUSSION AND CONCLUSION}

A model has been proposed in this study to investigate the factors that affect knowledge sharing attitude and IKS among employees of Islamic banks, while the TRA has been selected as the theoretical perspective. It has been found that all the proposed relationships are accepted except the two. Results were consistent with TRA (Fishbein \& Ajzen 1977) and other previous studies (Bock et al., 2005; Lin, 2007; Palo \& Charles, 2015).

Results show positive relation between attitude and intentions. It is found that the OBSE and SSW have positive significant influence on attitude. Further, by using Dominance Analysis (DA) it is found that OBSE has the most strong positive influence on knowledge sharing attitude, among all others, with the path coefficient of $\beta=0.41$. It means that Islamic banks support is highly appreciated by employees working there and they feel that they have esteem based on the Islamic banks. Therefore, Islamic banks should pay special focus on their support for employees which ultimately boost their KS feature. Similarly, SSW results are consistence with previous studies (Kankanhalli, Tan, \& Wei, 2005; Phan, 2013). Results support that employees are encouraged to sharing knowledge when they get positive feedback regarding their shared knowledge and find their knowledge to be useful for other employees and organization. Continuous feedback management system could be helpful for encouraging employees by showing usefulness of their shared knowledge. 
Remaining two factors i.e., ARR and AER have no effect on attitude. Results for ARR contradict with previous studies (Bock et al., 2005; Palo \& Charles, 2015; Phan, 2013). The negative result could be due to cultural differences as previous studies were conducted in western culture and this study is conducted in Pakistani culture. Organization culture and relationship among colleagues can influence employees KS behavior (Razmerita, Kirchner, $\&$ Nielsen, 2016). Likewise, results of AER also contradict with previous studies which found AER negatively influencing attitude (Bock et al., 2005; Fullwood \& Rowley, 2017; Seba et al., 2012). It means that AER could change employee's attitude for short period only, it works just as a trigger (Kohn, 1993). Therefore, reward system is not necessary for increasing KS. The inconsistent results of AER show that there might be possibility of moderators like contextual condition or personality, etc.

\section{Theoretical Implications}

This study investigates the relationship between factors affecting ATKS and IKS among employees of the Islamic banks. Islamic banks have so far created their separate identity among financial institutions. The rapid growth and innovation of financial products to cater the needs of customer in the light of Islamic rules made Islamic banks not only popular, but also made it a contributor to growth of economy as the people are increasingly adopting Islamic banking. However, despite growing importance of Islamic banks, researchers pay little attention to Islamic banks specifically on KS which is key element for the growing institutions or organizations. Keeping an eye on importance of Islamic banks in modern world, the unique contribution of this research is investigating factors that affect KS among Islamic banking employees. Previously, researchers had confirmed the relationship in other industries, this study specially focused on Islamic bank to test the relationship.

The proposed model investigated the factors affecting knowledge sharing attitude and intention. The study empirically confirms the relationship between motivational factors, attitude and intention. It finds that SSW and OBSE have significant positive effect on attitude, while AER and ARR have no effect on attitude. Result of SSW and OBSE are similar to that of the previous studies, while that of AER and ARR, are contradicting to previous studies. Further, it finds that knowledge sharing attitude has positive effect on IKS. Difference in results may be due to difference of culture, organization structure, etc.

\section{Practical Implications}

Following recommendations can be made for Islamic banking industry on the basis of the results of the study: Firstly, the study found that AER had no effect on attitude. It shows that Islamic banks should not go for the rewards system, they should adopt alternative methods to improve KS. Secondly, result of ARR shows no effect on attitude; hence, Islamic banks should pay more attention on relationship building to encourage KS. Orientations, communities formation, informal gathering should be conducted to improve KS. Thirdly, to further improve KS, efficient feedback system may be developed to improve KS. Further, special motivational seminars should be arranged to improve self-efficacy, which ultimately enhances KS. Last, but not the least, Islamic banks can boost KS by ensuring proper career 
plans and educational support.

\section{Limitations and Future Study}

For this study, Sample of 313 was drawn from Islamic banking industry. However, larger sample size could give more appropriate results. Further, to confirm the generalizability of the proposed model, it can be tested in different settings. To confirm the effect of factor, long term longitudinal data might be analyzed. Second, the study used TRA as base theory; in future TPB might be adopted for investigating sharing of knowledge. Third, current study only focused on some of the preceding factors; however, to get better picture it is suggested that future studies should also include other factors like 'loss of power', 'organizational commitments' etc. Forth, in future studies, researcher may pay attention to other influential and moderator variables, like trust, technology, loss of power, organizational commitment, time, organizational structure, gender, etc.

\section{REFERENCES}

Alam, S. S., Janor, H., Zanariah, C. A. C. W., \& Ahsan, M. N. (2012). Is religiosity an important factor in influencing the intention to undertake Islamic home financing in Klang Valley. World Applied Sciences Journal, 19(7), 1030-1041.

Alavi, M., \& Leidner, D. E. (2001). Knowledge management and knowledge management systems: Conceptual foundations and research issues. MIS Quarterly, 25(1), 107-136. doi: https://doi.org/10.2307/3250961

Arshad, M., Aslam, S., Razi, A., \& Ali, S. A. (2011). A comparative analysis of bankers' perception on Islamic banking in Pakistan. International Journal of Economics and Research, 2(4), 1-12.

Baba, R., \& Amin, H. (2009). Offshore bankers' perception on Islamic banking niche for Labuan: An analysis. International Journal of Commerce and Management, 19(4), 293-308. doi: https://doi.org/10.1108/10569210911008476

Bandura, A. (1994). Self-efficacy. In Encyclopedia of human behavior. London, UK: Academic Press.

Berman, S. L., Down, J., \& Hill, C. W. (2002). Tacit knowledge as a source of competitive advantage in the national basketball association. Academy of Management Journal, 45(1), 13-31. doi: https://doi.org/10.5465/3069282

Bentler, P. M., \& Bonett, D. G. (1980). Significance tests and goodness of fit in the analysis of covariance structures. Psychological Bulletin, 88(3), 588-606. doi: http://dx.doi.org/10.1037/0033-2909.88.3.588

Bock, G. W., Zmud, R. W., Kim, Y. G., \& Lee, J. N. (2005). Behavioral intention formation in knowledge sharing: Examining the roles of extrinsic motivators, socialpsychological factors, and organizational climate. MIS Quarterly, 29(1), 87-111. doi: https://doi.org/10.2307/25148669

Bock, G., \& Kim, Y. (2001). Breaking the myths of rewards: An exploratory study of attitudes about knowledge sharing. Paper presented at the Pacific Asia Conference on Information Systems. Retrieved from https://bit.ly/2XyuYSM 
Brockner, J. (1988). Self-esteem at work: Theory, research, and practice. Lexington, MA: Lexington Books.

Brown, J. D., \& Marshall, M. A. (2006). The three faces of self-esteem. Self-esteem: Issues and answers. New York, NY: Psychology Press.

Butler, B., Sproull, L., Kiesler, S., \& Kraut, R. (2002). Community effort in online groups: Who does the work and why. Leadership at a Distance: Research in Technologically Supported Work, 1, 171-194.

Cabrera, A., \& Cabrera, E. F. (2002). Knowledge-sharing dilemmas. Organization Studies, 23(5), 687-710. doi: https://doi.org/10.1177/0170840602235001

Casimir, G., Lee, K., \& Loon, M. (2012). Knowledge sharing: Influences of trust, commitment and cost. Journal of Knowledge Management, 16(5), 740-753.

doi: https://doi.org/10.1108/13673271211262781

Chen, C. J., \& Hung, S. W. (2010). To give or to receive? Factors influencing members' knowledge sharing and community promotion in professional virtual communities. Information $\mathcal{E}$ Management, 47(4), 226-236. doi: https://doi.org/10.1016/j.im.2010.03.001

Chennamaneni, A., Teng, J. T., \& Raja, M. K. (2012). A unified model of knowledge sharing behaviours: Theoretical development and empirical test. Behaviour $\mathcal{F}$ Information Technology, 31(11), 1097-1115. doi: https://doi.org/10.1080/0144929X.2011.624637

Chiu, C. M., Hsu, M. H., \& Wang, E. T. (2006). Understanding knowledge sharing in virtual communities: An integration of social capital and social cognitive theories. Decision Support Systems, 42(3), 1872-1888. doi: https://doi.org/10.1016/j.dss.2006.04.001

Davenport, T. H. (1996). Some principles of knowledge management. Strategy $\mathcal{E}$ Business, $1(2), 34-40$.

Davenport, T. H., \& Prusak, L. (1998). Working knowledge: How organizations manage what they know. Boston, MA: Harvard Business Press.

Dyer, J. H., \& Nobeoka, K. (2000). Creating and managing a highperformance knowledgesharing network: The Toyota case. Strategic Management Journal, 21(3), 345-367. doi: https://doi.org/10.1002/(SICI)1097-0266(200003)21:3<345::AID-SMJ96>3.0.CO;2-N

Edbiz, C. (2015). Global Islamic finance report. Retrieved from https://bit.ly/2EoxuU4

Fishbein, M., \& Ajzen, I. (1977). Belief, attitude, intention, and behavior: An introduction to theory and research. Journal of Business Venturing 5, 177-I89.

Ford, D. P., \& Staples, S. (2010). Are full and partial knowledge sharing the same? Journal of Knowledge Management, 14(3), 394-409.

doi: https://doi.org/10.1108/13673271011050120

Fornell, C., \& Larcker, D. F. (1981). Evaluating structural equation models with unobservable variables and measurement error. Journal of Marketing Research, 18(1), 39-50.

Fullwood, R., \& Rowley, J. (2017). An investigation of factors affecting knowledge sharing amongst UK academics. Journal of Knowledge Management, 21(5), 1254-1271. doi: https://doi.org/10.1108/JKM-07-2016-0274 
Gliem, J. A., \& Gliem, R. R. (2003). Calculating, interpreting, and reporting cronbach's alpha reliability coefficient for likert-type scales. Paper presented at the Midwest Researchto-Practice Conference in Adult, Continuing, and Community Education, Columbus, $\mathrm{OH}$.

Gupta, B., Joshi, S., \& Agarwal, M. (2012). The effect of expected benefit and perceived cost on employees' knowledge sharing behavior: A study of IT employees in India. Organizations $\mathcal{E}$ Markets in Emerging Economies, 3(1), 8-19.

Hair, J. F., Anderson, R. E., Babin, B. J., \& Black, W. C. (2010). Multivariate data analysis: A global perspective (Vol. 7): Upper Saddle River, NJ: Pearson. doi: https://doi.org/10.1016/j.jmva.2009.12.014

Hair, J. F., Black, W. C., Babin, B. J, Anderson, R. E, \& Tatham, R. L. (1998). Multivariate data analysis (5th ed). Upper Saddle River, NJ: Pearson.

Harun, T. W. R., Rashid, R. A., \& Hamed, A. B. (2015). Factors influencing products' knowledge of Islamic banking employees. Journal of Islamic Studies and Culture, 3(1), 23-33. doi: https://doi.org/10.15640/jisc.v3n1a4

Hsu, M. H., Ju, T. L., Yen, C. H., \& Chang, C. M. (2007). Knowledge sharing behavior in virtual communities: The relationship between trust, self-efficacy, and outcome expectations. International Journal of Human-Computer Studies, 65(2), 153-169. doi: https://doi.org/10.1016/j.ijhcs.2006.09.003

Hu, L. T., \& Bentler, P. M. (1999). Cutoff criteria for fit indexes in covariance structure analysis: Conventional criteria versus new alternatives. Structural Equation Modeling: A Multidisciplinary Journal, 6(1), 1-55.

Huang, E. Y., \& Huang, T. K. (2012). Investigating the antecedents of users' knowledge sharing intention. Journal of Computer Information Systems, 53(2), 93-102.

Huang, Q., Davison, R. M., \& Gu, J. (2008). Impact of personal and cultural factors on knowledge sharing in China. Asia Pacific Journal of Management, 25(3), 451-471. doi: https://doi.org/10.1007/s10490-008-9095-2

Huber, G. P. (2001). Transfer of knowledge in knowledge management systems: Unexplored issues and suggested studies. European Journal of Information Systems, 10(2), 72-79. doi: https://doi.org/10.1057/palgrave.ejis.3000399

Irma, B. R. S. (2001). Organizational knowledge management: A contingency perspective. Journal of Management Information Systems, 18(1), 23-55. doi: https://doi.org/10.1080/07421222.2001.11045676

Javernick-Will, A. (2011). Motivating knowledge sharing in engineering and construction organizations: Power of social motivations. Journal of Management in Engineering, 28(2), 193-202. doi: https://doi.org/10.1061/(ASCE)ME.1943-5479.0000076

Jeon, S., Kim, Y. G., \& Koh, J. (2011). An integrative model for knowledge sharing in communities-of-practice. Journal of Knowledge Management, 15(2), 251-269. doi: https://doi.org/10.1108/13673271111119682

Judge, T. A., \& Bono, J. E. (2001). Relationship of core self-evaluations traits-self-esteem, generalized self-efficacy, locus of control, and emotional stability-with job satisfaction and job performance: A meta-analysis. Journal of Applied Psychology, 86(1), 80-92. doi: https://doi.org/10.1037/0021-9010.86.1.80 
Kankanhalli, A., Tan, B. C., \& Wei, K. K. (2005). Contributing knowledge to electronic knowledge repositories: An empirical investigation. MIS Quarterly, 29(1), 113-143. doi: https://doi.org/10.2307/25148670

Khir, K., Gupta, L., \& Shanmugam, B. (2007). Islamic banking: A practical perspective. Kuala Lumpur, Malaysia: Institut Bank-Bank Malaysia.

Kinch, J. W. (1973). Social psychology. San Francisco, CA: McGraw-Hill Book Company.

Kline, R. B. (2011). Principles and practice of structural equation modeling. New York, NY: Guilford Press.

Kohn, A. (1993). Why incentive plans cannot work. Retrieved from https://bit.ly/2TIVUpO

Korman, A. K. (1970). Toward an hypothesis of work behavior. Journal of Applied psychology, 54, 31-41. doi: https://doi.org/10.1037/h0028656

Kwok, S. H., \& Gao, S. (2005). Attitude towards knowledge sharing behavior. Journal of Computer Information Systems, 46(2), 45-51.

Lamb, E. C. (2001). Knowledge management: How to mine the information treasures inside your bank: A tale of measuring and managing the potential within. Community Banker, 10(9), 24-26.

Lin, F. R., \& Huang, H. Y. (2013). Why people share knowledge in virtual communities? The use of Yahoo! Kimo Knowledge+ as an example. Internet Research, 23(2), 133159. doi: https://doi.org/10.1108/10662241311313295

Lin, H. F. (2007). Effects of extrinsic and intrinsic motivation on employee knowledge sharing intentions. Journal of Information Science, 33(2), 135-149. doi: https://doi.org/10.1177/0165551506068174

Liu, C. C. (2008). The relationship between machiavellianism and knowledge sharing willingness. Journal of Business and Psychology, 22(3), 233-240. doi: https://doi.org/10.1007/s10869-008-9065-1

Nonaka, I., \& Konno, N. (1998). The concept of "Ba": Building a foundation for knowledge creation. California Management Review, 40(3), 40-54. doi: https://doi.org/10.2307/41165942

Osterloh, M., \& Frey, B. S. (2000). Motivation, knowledge transfer, and organizational forms. Organization Science, 11(5), 538-550. doi: https://doi.org/10.1287/orsc.11.5.538.15204

Ozlati, S. (2012). Motivation, trust, leadership, and technology: Predictors of knowledge sharing behavior in the workplace (Unpublished doctoral dissertation). Claremont Graduate University, Claremont, CA.

Pai, J. C. (2006). An empirical study of the relationship between knowledge sharing and IS/IT Strategic Planning (ISSP). Management Decision, 44(1), 105-122. doi: https://doi.org/10.1108/00251740610641490

Palo, S., \& Charles, L. (2015). Investigating factors affecting knowledge sharing intention of salespeople. Management and Labour Studies, 40(3-4), 302-324. doi: https://doi.org/10.1177/0258042X16650048

Phan, T. H. L. (2013). An empirical study on factors affecting knowledge sharing intention in Vietnam. Retrieved from https://bit.ly/2Caq6dN 
Pierce, J. L., \& Gardner, D. G. (2004). Self-esteem within the work and organizational context: A review of the organization-based self-esteem literature. Journal of Management, 30(5), 591-622. doi: https://doi.org/10.1016/j.jm.2003.10.001

Pierce, J. L., Gardner, D. G., Cummings, L. L., \& Dunham, R. B. (1989). Organizationbased self-esteem: Construct definition, measurement, and validation. Academy of Management Journal, 32(3), 622-648. doi: https://doi.org/10.2307/256437

Razmerita, L., Kirchner, K., \& Nielsen, P. (2016). What factors influence knowledge sharing in organizations? A social dilemma perspective of social media communication. Journal of Knowledge Management, 20(6), 1225-1246.

doi: https://doi.org/10.1108/JKM-03-2016-0112

Scott, I. A. (1999). Opinion: What is a chief knowledge officer. Sloan Management Review, 40(2), 29-38.

Seba, I., Rowley, J., \& Lambert, S. (2012). Factors affecting attitudes and intentions towards knowledge sharing in the Dubai police force. International Journal of Information Management, 32(4), 372-380. doi: https://doi.org/10.1016/j.ijinfomgt.2011.12.003

Segars, A. H., \& Grover, V. (1998). Strategic information systems planning success: An investigation of the construct and its measurement. MIS Quarterly, 22(2), 139-163. doi: https://doi.org/10.2307/249393

Seyal, A. H., Rahman, M. N. A., \& Rahim, M. M. (2002). Determinants of academic use of the internet: A structural equation model. Behaviour $\mathcal{E}$ Information Technology, 21(1), 71-86.

Sharma, B. P., \& Singh, M. D. (2012). Knowledge sharing barriers: An approach of interpretive structural modeling. IUP Journal of Knowledge Management, 10(3), 35-52.

Shih, K. H., Chang, C. J., \& Lin, B. (2010). Assessing knowledge creation and intellectual capital in banking industry. Journal of Intellectual Capital, 11(1), 74-89. doi: https://doi.org/10.1108/14691931011013343

Søndergaard, S., Kerr, M., \& Clegg, C. (2007). Sharing knowledge: Contextualising sociotechnical thinking and practice. The Learning Organization, 14(5), 423-435.

doi: https://doi.org/10.1108/09696470710762646

Staples, D. S., \& Webster, J. (2008). Exploring the effects of trust, task interdependence and virtualness on knowledge sharing in teams. Information Systems Journal, 18(6), 617-640. doi: https://doi.org/10.1111/j.1365-2575.2007.00244.x

State Bank of Pakistan. (Mar, 2018). Islamic banking bulletin. Karachi, Pakistan: State Bank of Pakistan.

Tohidinia, Z., \& Mosakhani, M. (2010). Knowledge sharing behaviour and its predictors. Industrial Management $\mathcal{E}$ Data Systems, 110(4), 611-631. doi: https://doi.org/10.1108/02635571011039052

Vajjhala, N. R. (2013). Key barriers to knowledge sharing in medium-sized enterprises in transition economies. International Journal of Business and Social Science, 4(14), 90-98.

Vuori, V., \& Okkonen, J. (2012). Knowledge sharing motivational factors of using an intra-organizational social media platform. Journal of Knowledge Management, 16(4), 592-603. doi: https://doi.org/10.1108/13673271211246167 
Ling, C., Sandhu, M. S., \& Jain, K. K. (2009). Knowledge sharing in an American multinational company based in Malaysia. Journal of Workplace Learning, 21(2), 125-142. doi: https://doi.org/10.1108/13665620910934825

Wang, S., \& Noe, R. A. (2010). Knowledge sharing: A review and directions for future research. Human Resource Management Review, 20(2), 115-131.

doi: https://doi.org/10.1016/j.hrmr.2009.10.001

Wang, Z., Sharma, P. N., \& Cao, J. (2016). From knowledge sharing to firm performance: A predictive model comparison. Journal of Business Research, 69(10), 4650-4658. doi: https://doi.org/10.1016/j.jbusres.2016.03.055

Wu, W. L., Yeh, R. S., \& Hung, H. K. (2012). Knowledge sharing and work performance: A network perspective. Social Behavior and Personality: An International Journal, 40(7), 1113-1120. doi: https://doi.org/10.2224/sbp.2012.40.7.1113

Yang, J. T. (2007). Knowledge sharing: Investigating appropriate leadership roles and collaborative culture. Tourism Management, 28(2), 530-543.

doi: https://doi.org/10.1016/j.tourman.2006.08.006

Ye, S., Chen, H., \& Jin, X. (2006). An empirical study of what drives users to share knowledge in virtual communities. Paper presented at the International Conference on Knowledge Science, Engineering and Management, Berlin, Germany. doi: https://doi.org/10.1007/11811220_48

Zainol, Z., Shaari, R., \& Ali, M. H. (2008). A comparative analysis on bankers' perceptions on Islamic banking. International Journal of Business and Management, 3(4), 157-168. Zhang, P., \& Fai Ng, F. (2012). Attitude toward knowledge sharing in construction teams. Industrial Management $\mathcal{E}$ Data Systems, 112(9), 1326-1347. doi: https://doi.org/10.1108/02635571211278956

Zhang, X., Chen, Z., Vogel, D., \& Guo, C. (2009). Exchange ideology as a moderator of knowledge sharing in virtual teams: A social exchange theory perspective. International Journal of Internet and Enterprise Management, 6(2), 143-163.

doi: https://doi.org/10.1504/IJIEM.2009.023927

Zhang, Y., \& Hiltz, S. R. (2003). Factors that influence online relationship development in a knowledge sharing community. AMCIS 2003 Proceedings. Retrieved from https://bit.ly/2SD7c4h 